\title{
Concepções da equipe escolar sobre as necessidades formativas e laborais dos alunos da inclusão
}

\author{
Cinthia Maria Felicio ${ }^{1}$ \\ Jullyana Pimenta Borges Gonçalves ${ }^{2}$
}

\section{RESUMO}

Este estudo, realizado em uma escola pública estadual em Caldas NovasGO, objetiva descrever a formação, práticas educativas e visão da equipe responsável sobre futura inserção de alunos com Necessidades Educacionais Especiais (NEE) no mundo do trabalho. Realizou-se um estudo de caso, de abordagem qualitativa, com uso de entrevista e questionário semiestruturado, aplicados aos coordenadores pedagógicos, professores de apoio (PA) à inclusão e professores regentes (PR) que atuam no Ensino Médio. Os resultados indicam a necessidade de formação docente continuada, voltada à educação inclusiva; melhoria quanto a realização de adequações para favorecer ao aluno com NEE; articulação entre PR e PA para colaboração visando ao desenvolvimento do aluno. Ademais, os responsáveis pela inclusão necessitam ser melhor sensibilizados quanto a relevância da mediação da aprendizagem, essenciais para que o aluno com NEE consiga futura inserção no mundo do trabalho, questão a ser repensada e melhor articulada pelos profissionais responsáveis pela inclusão.

PALAVRAS-CHAVE: Formação Docente. Educação Inclusiva. Capacidade Laboral. Necessidades Educacionais Especiais.

School staff conceptions for the inclusion needs of students

\footnotetext{
ABSTRACT

${ }^{1}$ Doutora em Química- Instituto Federal de Educação, Ciência e Tecnologia Goiano-Campus Morrinhos, Morrinhos, Goiás, Brasil. https://orcid.org/0000-0002-8362-2846. cinthia.felicio@ifgoiano.edu.br.

${ }^{2}$ Mestra em Educação Profissional e Tecnológica. Instituto Federal de Educação, Ciência e Tecnologia GoianoCampus Morrinhos, Morrinhos, Goiás, Brasil. https://orcid.org/0000-0003-3341-2303. jullyanapbg@ gmail.com.
} 
This study, conducted in a public school in Caldas Novas-GO, aims to describe the training, educational practices and participants' view of the future insertion of students with Special Educational Needs (SEN) in the work. A qualitative case study was conducted using a semi-structured interview and questionnaire, applied to the pedagogical coordinators, inclusion support teachers and teachers who work in this high school. The results pointed to the need for: continuing teacher education, focused on inclusive education; improvement in making adequacy of conditions to favor the student with SEN; articulation between teachers and inclusion support teachers for a collaborative work aimed at student learning. In addition, those responsible for inclusion need to be better sensitized about the relevance of learning mediation, which is essential for students with SEN to find a future insertion in the world work, an issue to be rethought and better articulated by professionals responsible for inclusion.

KEYWORDS: Teacher Training. Inclusion. Labor Capacity. Special Educational Needs.

\section{Introdução}

No Brasil, a inclusão de alunos com Necessidades Educacionais Especiais (NEE) na escola regular foi estimulada principalmente pela atual Constituição (BRASIL, 1988) e pela Declaração de Salamanca (UNESCO, 1994), documentos onde há o reconhecimento do acesso à educação como um direito de todos, independente de suas condições físicas, intelectuais ou sociais. Antes de 1961, a educação dos alunos com deficiência era realizada num modelo de segregação, em que eles eram encaminhados para classes e escolas especiais, que cuidavam exclusivamente de alunos com deficiência (MAZZOTTA, 2011).

Após esse período, temos a promulgação de duas Leis de Diretrizes e Bases da Educação (BRASIL, 1961; BRASIL, 1971) que nesse sentido, expressaram a tentativa de integração dos alunos com deficiência na escola 
regular, porém usaram o termo "preferencialmente" para designar o encaminhamento às escolas regulares, o que justificou a continuidade do modelo que incluía alguns e excluía outros, com maiores dificuldades de adaptação (MAZZOTTA, 2011). Já a atual LDB (BRASIL, 1996) prevê um modelo inclusivo que visa romper com a perspectiva de segregação e promover a integração, em que as escolas comuns se organizem visando atender às necessidades dos alunos e sejam um local para o acolhimento de todos.

Assim, “[...] os sistemas de ensino devem matricular todos os estudantes, cabendo às escolas organizarem-se [...] assegurando as condições necessárias para uma educação de qualidade para todos” (BRASIL, 2001, Artigo 2). Nesse sentido, Jesus e Effgen (2012) ressaltam as mudanças necessárias para a promoção da inclusão, como adequações curriculares, metodológicas e das avaliações:

Para a garantia da aprendizagem de todos os alunos, precisamos assegurar o acesso ao currículo escolar, por meio de práticas pedagógicas diferenciadas que atendam aos percursos de aprendizagem de cada estudante. Tal situação é um desafio, pois demanda professores detentores de conhecimentos teóricopráticos, bem como planejamentos coletivos, estratégias e metodologias de ensino e de processos de avaliação que possibilitem ao educador acompanhar o desenvolvimento de cada aluno que está em sala de aula (JESUS; EFFGEN, 2012, p. 20).

Garcia (2013) mostra que as diretrizes para a formação de professores para o atendimento dos alunos com NEE têm como foco o profissional do Atendimento Educacional Especializado (AEE) (BRASIL, 2009) e o intérprete de Libras (BRASIL, 2005), assim, os docentes com formação nas áreas das diferentes licenciaturas e que também lidam cotidianamente com os alunos, têm pouco contato com conteúdos relacionados à educação especial. À essa questão Saviani (2009) alerta, evidenciando a importância de se trabalhar 
mais atentamente a formação de professores para a inclusão, afirmando que “[...] será necessário instituir um espaço específico para cuidar da formação de professores para essa modalidade de ensino. Do contrário essa área continuará desguarnecida [...]" (SAVIANI, 2009, p. 153).

Portanto, uma formação docente que oriente os professores sobre as especificidades da educação inclusiva e que fundamente um trabalho reflexivo baseado no respeito a diversidade é essencial (NASCIMENTO, 2009). Mantoan (2015) colabora dizendo que as práticas docentes devem ter como principal objetivo o desenvolvimento da autonomia do estudante, para que ele consiga efetiva inserção no ambiente escolar, social e futuramente, no ambiente profissional.

Dell-Masso (2012) ainda acrescenta a dificuldade enfrentada pelos alunos público-alvo da educação inclusiva quando almejam inserção no mundo do trabalho, mostrando a importância de um preparo escolar adequado. Para a autora, a escola deve se comprometer na construção de um projeto inclusivo que vislumbre o futuro acesso ao trabalho como uma continuidade do processo educacional, assim "[...] cabe à escola incluir em seu currículo informações sobre o mundo do trabalho, preparando o aluno para a autonomia, cidadania e para a própria vida” (DELL-MASSO, 2012, p. 427).

Entre as três etapas da educação básica, a última (Ensino Médio) é a que mais se aproxima da fase de preparação para o mundo do trabalho (BRASIL, 1996) e estamos em um período de transição para a concretização das mudanças previstas na lei $\mathrm{n}^{0} 13.415 / 17$ que dispõe sobre a Reforma do Ensino Médio (BRASIL, 2017). Essa reforma propõe uma nova configuração e determina que a trajetória escolar no Ensino Médio seja dividida em dois pilares: um de formação geral básica e outro composto por itinerários formativos. Entre esses itinerários formativos, deverá existir a oferta de formação técnica e profissional para que os estudantes que assim desejarem, possam receber uma formação profissionalizante (BRASIL, 2018). 
Porém, para o aluno com deficiência a profissionalização é um desafio, com barreiras de preconceitos e estigmas que só serão minimizados se esse estudante receber uma formação capaz de promover a mediação para o mundo do trabalho (REDIG; GLAT, 2017). Essa questão não deve ser negligenciada no processo educacional dos alunos, por isso os docentes são agentes fundamentais no processo de desmistificação de paradigmas excludentes, sendo necessário reconhecê-los e enfrentá-los (DELL-MASSO, 2012).

No delineamento do itinerário formativo voltado à educação profissional, a ser implementado pelas instituições para atender a nova configuração do Ensino Médio (BRASIL, 2018), é necessário que a equipe escolar (re)pense a relação entre trabalho e educação. Essa reflexão torna-se essencial para que as práticas prescritas pela nova lei sejam condizentes com um projeto de emancipação dos alunos e não seja mera preparação para o mercado de trabalho competitivo.

Silva (2018) critica a maneira como a reforma do Ensino Médio (BRASIL, 2017) foi imposta ao contexto escolar, sem consulta ou participação efetiva dos educadores, e acrescenta que as supostas mudanças na verdade são o resgate de antigos discursos baseados na noção de competências. Para a autora, a reforma traz consigo uma orientação para a formação pragmática, por isso tecnicista, visando formar estudantes/trabalhadores para o mercado de trabalho, portanto não prima pela formação integral do aluno.

Em contrapartida, se entendermos o trabalho sob a perspectiva ontológica, veremos que é por meio dele que o ser humano se diferencia dos outros animais, portanto o trabalho é inerente ao ser do homem, o acompanha desde sua origem, por intermédio dele transforma a natureza em seu benefício e expressa sua racionalidade (SAVIANI, 2007). Nessa perspectiva, o trabalho é verdadeiramente um princípio educativo:

[...] a relação entre trabalho e educação é uma relação de 
identidade. Os homens aprendiam a produzir sua existência no próprio ato de produzi-la. Eles aprendiam a trabalhar trabalhando. Lidando com a natureza, relacionando-se uns com os outros, os homens educavam-se e educavam as novas gerações. A produção da existência implica o desenvolvimento de formas e conteúdos cuja validade é estabelecida pela experiência [...] (SAVIANI, 2007, p. 154).

Assim, conforme o autor explica, separar o trabalho manual do intelectual é separar o próprio ser do homem e negar-lhe um ou outro fundamento vital. Com esse entendimento, sinaliza a necessidade de um modelo educacional que una formação intelectual e trabalho produtivo, aprendizado intelectual e manual. É sobre essa base que o Ensino Médio e a formação profissional devem se erigir, reconhecendo a indissociabilidade entre a prática e o conhecimento teórico (RAMOS, 2008).

Para Saviani (2007), a organização do Ensino Médio baseada no trabalho como princípio educativo deve explicitar a relação entre trabalho e educação, entre prática e teoria, para o alcance da formação politécnica ou formação integral. De acordo com Ciavatta e Ramos (2011), o Ensino Médio ideal também é o integrado, ou seja, que contemple a formação geral e a preparação para o mundo do trabalho, na visão omnilateral, de formar pessoas emancipadas, capazes de compreender a sociedade em que estão inseridas e agir sobre ela, modificando-a. Dessa forma:

Como formação humana, o que se busca é garantir ao adolescente, ao jovem e ao adulto trabalhador o direito a uma formação completa para a leitura do mundo e para a atuação como cidadão pertencente a um país, integrado dignamente à sua sociedade política. Formação que, nesse sentido, supõe a compreensão das relações sociais subjacentes a todos os fenômenos (CIAVATTA, 2005, p. 02). 
Moura (2007) colabora ao defender que a oferta do Ensino Médio no Brasil precisa estar voltada “[...] à formação de cidadãos capazes de compreender a realidade social, econômica, política, cultural e do mundo do trabalho para nela inserir-se e atuar de forma ética e competente [...]" (MOURA, 2007, p. 20). Para o autor, é viável a integração entre Ensino Médio e ensino profissional, com pressupostos que enxergam o homem como um ser histórico-social, o trabalho e a pesquisa como princípios educativos, a realidade dialética, portanto passível de mudanças, e considerando a interdisciplinaridade, contextualização e flexibilidade como norteadoras da atividade pedagógica.

Quanto às estratégias para promover a inclusão dos alunos com NEE, a “[...] organização e prática pedagógica devem respeitar a diversidade dos alunos, a exigir diferenciações nos atos pedagógicos que contemplem as necessidades educacionais de todos" (ARANHA, 2003, p. 26). Sendo assim, para que todos os alunos possam ser atendidos em suas especificidades no processo de construção do conhecimento, é necessário possibilitar “[...] percursos diferenciados que permitam atingir as mesmas metas finais, configurando formas de adequação curricular" (SILVA; LEITE, 2015, p. 46).

Dessa forma, refletimos sobre as seguintes questões norteadoras: Os coordenadores pedagógicos e docentes têm formação relacionada à educação inclusiva que os direcione ao uso de metodologias e práticas educativas de modo a favorecer a aprendizagem dos discentes público da educação inclusiva? Quais são as concepções desses agentes educativos sobre o potencial laboral dos alunos com NEE e futura inserção no mundo do trabalho?

Ponderando a esse respeito, partimos do pressuposto que uma formação docente frágil no que diz respeito a preparação para o atendimento dos alunos com NEE dificulta o desenvolvimento de práticas educativas que favoreçam a aprendizagem e a futura inserção deles no mundo do trabalho.

Sendo assim, o objetivo geral desse estudo foi identificar as concepções dos coordenadores pedagógicos, dos professores regentes e dos 
professores de apoio à inclusão a respeito da futura inserção dos alunos com NEE no mundo do trabalho. Como objetivos específicos tencionamos elencar as práticas inclusivas relatadas por esses profissionais e descrever a visão deles em relação a futura inserção dos alunos no mundo do trabalho. E por fim, apresentar um produto educacional que possa contribuir com a formação docente continuada no âmbito da educação inclusiva e sua relação com o mundo trabalho.

\section{Percurso metodológico}

O presente estudo é resultado de uma pesquisa, cujo projeto foi submetido ao Comitê de Ética em Pesquisa (CEP), do Instituto Federal de Educação, Ciência e Tecnologia Goiano e aprovado por meio do parecer $\mathrm{n}^{\mathrm{o}}$ 3.061.817. Trata-se de pesquisa com abordagem qualitativa, pautada na pesquisa bibliográfica sobre a temática tratada e pesquisa de campo, do tipo estudo de caso (LAKATOS; MARCONI, 2003). Conforme orientam Ghedin e Franco (2011), a abordagem qualitativa é a mais indicada quando se realiza pesquisa na área da educação e ensino que busque aproximação com o objeto de estudo, para percebê-lo em diversas dimensões, considerando a realidade dialética em que os fenômenos educativos estão inseridos.

A pesquisa bibliográfica foi feita por meio de análise textual, análise temática e análise interpretativa de livros, artigos e leis (SEVERINO, 2007). Já a opção em realizar um estudo de caso se deu porque a proposta da pesquisa é aprofundar o conhecimento sobre um grupo específico e porque permite a abrangência de diferentes aspectos de um mesmo objeto (YIN, 2015).

Como instrumentos de coleta de dados optou-se por questionário e entrevista semiestruturada, com cinco (05) perguntas abertas. As questões foram estruturadas para que os participantes pudessem discorrer sobre a sua formação acadêmica e atuação, percepções e vivências em relação ao público-alvo da educação inclusiva e possibilidades de inserção no mundo do 
trabalho. Participaram da pesquisa cinco (05) professoras de apoio à inclusão, 26 professores regentes e quatro (04) coordenadores pedagógicos.

Quanto aos questionários, são instrumentos de coleta de dados compostos de questões, as quais devem ser respondidas por escrito, destinadas a obter informações sobre o tema de estudo da pesquisa (GIL, 2008). Em nossa proposta, os questionários foram aplicados aos professores regentes. Já a entrevista é um instrumento de coleta de dados que visa obter informações do entrevistado sobre um determinado assunto, oportuniza ao entrevistado discorrer sobre o tema com liberdade, além disso, dá ao entrevistador a possibilidade de esclarecer possíveis dúvidas em relação às perguntas e certo controle em relação aos objetivos das questões (MINAYO, 2002). A entrevista foi realizada com os coordenadores pedagógicos e professores de apoio.

Para garantir a fidedignidade das respostas, as entrevistas foram gravadas com a utilização do aplicativo Gravador de Voz, do celular da pesquisadora e transcritas na íntegra, por meio da ferramenta Digitação por Voz, encontrada no pacote de aplicativos conhecido como Google DOCS, para posterior análise. Todas as transcrições foram cuidadosamente revisadas pela pesquisadora a fim de garantir a integralidade das entrevistas.

Os dados coletados foram digitados e os participantes foram identificados com códigos, para que pudéssemos nos referir a eles com garantia de anonimato. A organização dos dados seguiu a sequência orientada por Lakatos e Marconi (2003), seleção, codificação e tabulação. Todas as respostas dos questionários e entrevistas foram agrupadas numa mesma página, em quadros, de acordo com cada questão, para que as respostas pudessem ser comparadas e depois categorizadas.

Durante a organização dos quadros, os participantes foram identificados com códigos, sendo assim, os quatro coordenadores foram identificados como C01, C02, $\mathrm{C} 03$ e C04. Os cinco professores de apoio, como PA01, PA02, PA03, PA04 E PA05. E os 26 professores regentes foram identificados como PR01, PR02 e assim sucessivamente até o último, PR26. 
Para a análise dos dados, buscamos identificar as relações existentes entre as respostas obtidas e outros fatores, a partir da análise de conteúdo, estabelecendo relação com o conhecimento teórico sobre o tema tratado, ou seja, ligação entre a teoria e a prática investigada (LAKATOS; MARCONI, 2003). Dessa maneira buscamos a “[...] apreensão de significados na fala dos sujeitos, interligada ao contexto em que eles se inserem [...]" (ALVES; SILVA, 1992, p. 65).

Durante a organização e análise dos dados coletados buscamos identificar alguns pontos de atenção, que pudessem nos direcionar na elaboração do Produto Educacional, exigência da Coordenação de Aperfeiçoamento de Pessoal de Nível Superior (CAPES) em Mestrados Profissionais. A elaboração do produto vem ao encontro do pensamento de que a pesquisa científica só faz sentido à medida que é compartilhada com a comunidade e pode contribuir com sua melhoria, nunca sendo arquivada, ao contrário, deve “[...] transformar-se em conteúdo de ensino [...]" (SEVERINO, 2007, p. 35).

\section{Resultados e discussões}

Quanto a formação dos 35 profissionais pesquisados, verificamos que somente 10 possuíam formação na área da educação inclusiva, sendo esses os cinco (05) Professores de Apoio (PA) à inclusão, três (03) coordenadores pedagógicos e somente dois (02) professores regentes (PR). Sendo assim, observamos que os PA e a coordenadora do Atendimento Educacional Especializado, contada entre os três referidos coordenadores, têm formação voltada à educação inclusiva, uma vez que esse é um requisito legal para o exercício de suas funções (BRASIL, 1996) junto aos alunos com NEE.

Porém, ponderamos que apenas 02 professores regentes terem cursos voltados à educação inclusiva é um número pouco expressivo. Principalmente se considerarmos que esses profissionais lidam com alunos que possuem diferentes necessidades educacionais no presente ano e terão 
que lidar com essas especificidades durante toda a sua trajetória profissional, afinal, o direito a educação é assegurado a todos (BRASIL, 2008).

A questão da formação ou a não formação voltada à educação inclusiva teve alguns desdobramentos no decorrer de nossas análises. Ao identificarmos os direcionamentos das ações realizadas pelos coordenadores junto aos professores (PA, PR) vimos que eles relataram práticas relacionadas à busca de diagnóstico dos alunos com NEE e orientação aos professores; Adaptação de atividades e flexibilização das provas (adaptação e flexibilização foram termos usados pelos participantes, consideramos, porém, que o termo adequações seja mais apropriado); contato permanente com os familiares e ampliação de materiais textuais.

Sobre o diagnóstico os coordenadores não definiram se há o uso de algum instrumento para isso, como ficha de anamnese ou de acompanhamento para a identificação dessas necessidades, demonstraram que fica a cargo dos professores por meio de suas observações e da lista de matrícula de alunos com NEE, em que consta o registro da necessidade educacional do estudante. Nesse caso, o diagnóstico fica baseado no modelo médico em que o foco é apontar limitações e déficits, quando no contexto escolar importa que se valorizem potencialidades que se constituam como elementos norteadores das práticas educativas, como esclarece Carvalho (2014):

Sintetizando, parece que o modelo médico destaca a condição de dependência permanente, como se todas as pessoas incapacitadas nunca pudessem ser autoras e mentoras de seus projetos de vida representando, em decorrência, um problema para a sociedade em que vivem [...] Todas as reflexões passam pelo questionamento das influências que tais classificações exercem na construção do imaginário coletivo acerca das deficiências e sobre as ações cabíveis para evitar os estigmas decorrentes (CARVALHO, 2014, p. 29). 
A esse respeito indagamos: a escola poderia construir seus próprios instrumentos para identificar as necessidades educacionais dos alunos, baseados em necessidades de aprendizagem e não de necessidades psicofisiológicas, superando o modelo médico? Esse modelo seria válido para a instituição Estado liberar a contratação de PA para acompanhar os alunos? Como os alunos com necessidades educacionais que não possuem laudo serão identificados? Poderão os professores, que não têm formação voltada à educação inclusiva identificar satisfatoriamente esses alunos?

As narrativas dos participantes refletiram ainda a complexidade da concretização do contexto que se propõe a ser inclusivo também relatando as dificuldades e até resistência dos PR em lidar com os alunos e com as diferenciações que o atendimento a eles demanda. Esse foi um comentário recorrente, expressado pelos coordenadores, PA e inclusive pelos próprios PR, o que é uma questão preocupante. Afinal, a aceitação, o acolhimento e as adequações são essenciais para que o aluno com NEE encontre um ambiente propício ao aprendizado (JESUS; EFFGEN, 2012).

Sobre os procedimentos de ensino e maneira como acompanham os alunos, os PA relataram práticas de assistência individualizada, orientação em relação as atividades propostas pelo professor regente, auxílio para que o aluno tenha acesso ao próprio material, uso de linguagem simplificada, priorização de conteúdos teóricos em detrimento à cálculos e uso de materiais pedagógicos concretos, adequações de atividades e provas, estímulo à independência, pesquisa complementar com o aluno e uso de calculadora.

Segundo as Diretrizes Operacionais (GOIÁS, 2016), no estado de Goiás as funções do PA se relacionam ao cuidado, atenção, apoio físico e pedagógico para que o estudante possa ser incluído no processo educacional. Ele deve ainda "[...] subsidiar o Professor Regente nas atividades com toda a turma [...]" (GOIÁS, 2016, p. 72). 
Os PA citaram algumas dificuldades dos alunos como a distração e falta de concentração, insegurança e dificuldades em relação as disciplinas das áreas exatas como matemática, física e química. Os relatos demonstraram preocupação com o aprendizado dos alunos e busca de alternativas que respeitem as suas especificidades, embora não possamos julgar a pertinência da priorização de conteúdos teóricos em detrimento à cálculos, sendo essa opção uma alternativa para casos específicos que não pode ser generalizada, com o risco de omitir oportunidades de aprendizagem ao aluno.

Ademais, dois (02) PA relataram existir um distanciamento entre eles e os PR e ainda entre os PR e os alunos a quem eles assistem, atribuindo invisibilidade ao aluno diante desse $\mathrm{PR}$, segundo um deles. O distanciamento ainda ficou evidenciado nas falas "[...] o professor regente [...] ele não está nem aí, nem nada [...]" (Resposta da questão 03, participante PA04) e "[...] parece que o aluno, ele não está ali [...]" (Resposta da questão 03, participante PA05).

Mousinho et al (2010) orientam que "[...] o mediador deveria ser encarado como um profissional que assume o papel de auxiliar na inclusão do aluno com deficiência e não o papel de professor principal da criança" (MOUSINHO et al, 2010, p. 95). Por isso nas atribuições do PA (GOIÁs, 2016) está direcionado que ele deve atuar de maneira integrada ao Professor Regente (PR), Professor de AEE e Coordenador Pedagógico. Vilaronga e Mendes (2014) contribuem dizendo que para que o aluno com NEE seja atendido de maneira satisfatória é necessário que haja um ensino colaborativo, em que PA e PR atuem em parceria.

Os relatos indicaram que não há um tempo dedicado à interação entre PA e PR, o que dificulta a construção de estratégias para a aprendizagem dos alunos, que deveriam ser articuladas por esses dois profissionais, em parceria, afinal o aluno está sob a responsabilidade dos dois profissionais, sendo incoerente que sua presença seja desapercebida pelo PR. À essa séria questão, Carvalho (2014, p. 59) acrescenta a necessidade de "[...] enfrentar 
as barreiras invisíveis, as mais dramáticas, e que se traduzem nas atitudes de muitos educadores, [...] que geram ações discriminatórias e excludentes”.

Em relação aos professores regentes e seus procedimentos de ensino nas salas com alunos público-alvo da educação inclusiva, obtivemos um grupo de professores que relatou o desenvolvimento de práticas diferenciadas, outro que relatou não realizar diferenciações ou delegar essa tarefa para o professor de apoio, um terceiro grupo que, apesar de buscar alternativas diferenciadas, expressou sentir dificuldades em relação ao atendimento dos alunos. $\mathrm{E}$ ainda um quarto grupo manifestou sentir-se incapaz diante dos alunos público-alvo da educação inclusiva.

Nesse sentido, falta conhecimento por parte dos PR sobre a realização de adequações curriculares, que devem ser ações pedagógicas e didáticas visando promover condições para que o aluno tenha acesso ao conteúdo curricular proposto, levando-se em consideração suas particularidades, sendo uma ação imprescindível para a aprendizagem dos alunos com NEE (JESUS; EFFGEN, 2012); (CARVALHO, 2014); (SILVA; LEITE, 2015).

Portanto, quando não realizam as adequações os professores demonstram falta de sensibilização e a compreensão de que todos aprendem da mesma forma, com uma postura homogeneizadora da turma (CARVALHO, 2014). Além disso, os professores que relataram deixar a cargo do PA realizá-las, evidenciam o distanciamento entre os dois profissionais e reforçamos que essa postura não é coerente com a perspectiva de ensino colaborativo, em que PA e PR sejam parceiros.

Ao grupo que manifestou sentir dificuldades em realizar diferenciações, os professores justificaram a quantidade de alunos nas salas, que dificulta a percepção das dificuldades e consequente atendimento, além disso reconheceram a falta de uma formação que os capacite a realizar tais diferenciações e ainda citaram a dificuldade de se trabalhar nas salas com o aluno com NEE sem o PA, que é também uma realidade vivenciada na escola pesquisada. De fato, as condições concretas de trabalho do professor não são ideais e isso implica negativamente inclusive em sua busca por 
formação continuada, conforme alertado por Saviani (2009) e que foi uma necessidade reconhecida pelos próprios profissionais pesquisados.

No entanto, os estudantes com NEE requerem intervenções com o uso de metodologias e práticas que atendam suas particularidades, assim, é necessário a busca por caminhos que possam equacionar essa questão. Nessa perspectiva, buscamos contribuir com o processo reflexivo de formação dos participantes da pesquisa por meio do produto educacional elaborado.

Quanto aos professores que se reconheceram incapazes em lidar com o público da educação inclusiva, também justificaram a falta de formação e capacitação, porém ao refletirmos sobre as respostas desse grupo, nos parece transparecer um maior distanciamento dos alunos, ficando a ideia de que eles são ignorados pelos profissionais que, resguardados pela justificativa da não formação, abstêm-se de se aproximar dos alunos. Conforme foi expressado que "Normalmente não direciono aula para o público da educação inclusiva porque não tenho capacitação para lidar com esse público [...]" (Resposta da questão 03, participante PR15).

O participante PR15 admitiu não direcionar a aula para o público da educação inclusiva, tal fala nos leva a refletir sobre a percepção de alunos com NEE sobre si mesmos por meio da mediação desse professor, que parece ser professor do outro, mas não dele. Certamente esse aluno percebe o não pertencimento ao grupo de alunos que serão ensinados e do qual ele não faz parte, uma situação lamentável. Zabala (1998) nos mostra uma compreensão pertinente a essa situação e a importância do professor acreditar e dispensar atenção aos seus alunos:

[...] dado o importante papel que desempenham as expectativas dos professores para com os alunos, será preciso encontrar em todos os alunos aspectos positivos (posto que sem dúvida existem) [...] por sua parte, meninos e meninas dos quais se esperavam poucos êxitos e que podem ter recebido uma ajuda educacional de 
menor qualidade também responderão às expectativas geradas ao não encontrar condições apropriadas para melhorar seu rendimento (ZABALA, 1998, p. 95)

Relacionado ao potencial laboral dos alunos com NEE e futura inserção destes estudantes no mundo do trabalho, os participantes relataram alguns meios pelos quais consideram que eles poderão ingressar no mundo do trabalho. Políticas públicas, cotas e concursos foram o meio de inserção mais mencionado pelos participantes, constando nas respostas de 14 deles. Mas ainda foram relacionados outros meios como apoio familiar, esforço e superação pessoal e escolarização para que o estudante consiga inserção no mundo do trabalho.

Os participantes acrescentaram também que essa inserção depende do tipo de necessidade/deficiência, relacionada a adequação do perfil ao cargo pretendido e um grupo menor constando em seis (06) respostas demonstrou maior criticidade ao considerar os desafios e as contradições presentes na pretensão da inserção destes estudantes no mundo do trabalho. Para esse grupo é necessária uma transformação da sociedade para tal alcance, como demonstrado na resposta do participante PR07:

Apesar de existir leis que obrigam a contratar pessoas com necessidades especiais, vejo isso como uma ação pequena frente as dificuldades que eles enfrentam. Ainda existe resistência por parte das empresas e empregadores. O governo, além de criar leis, deveria investir em núcleos de formação, não só para pessoas com necessidades especiais, mas também, para pessoas "ditas normais" não sei qual expressão correta para esse caso. E, após essa formação encaminhá-los para o mercado de trabalho oferecendolhes também mais oportunidades. Só que isso, por si só, também não basta. $\mathrm{O}$ acesso às universidades, por pessoas com necessidades especiais, também é pequena. E não podemos pensar exclusivamente nesse contingente somente como mão-de-obra para 
o trabalho. Dar-lhes condições de acesso a uma formação humana mais ampla também é seu direito. (Resposta da questão 04, participante PR07)

A resposta desse participante é congruente aos desafios expostos por Leme (2015) que, ao apresentar a relação entre deficiência e trabalho mostra a complexidade de fatores que intervêm na questão. Para a autora é necessário que haja realmente uma mudança na forma como a sociedade enxerga e se organiza diante das pessoas com deficiência.

Importa ressaltar que a escolarização foi o meio citado em apenas seis (06) respostas, (e também considerada pelo grupo que prevê transformação da sociedade) demonstrando que grande parte dos participantes, apesar de serem profissionais da educação, não reconhecem a escolaridade como meio de promover o acesso dos alunos ao mundo do trabalho. Carecendo assim que sejam despertados para o reconhecimento da necessidade de melhoria no processo educativo dos alunos com NEE para que eles possam ser incluídos também no mundo do trabalho (DELL-MASSO, 2012), já que tal preparação é um dos objetivos do Ensino Médio (BRASIL, 2017). Leme (2015) também contribui nesse sentido, destacando a importância do professor nesse processo:

\footnotetext{
Observa-se uma preocupação em garantir o acesso do aluno com deficiência às instituições de ensino e ao próprio conhecimento. Seria importante, no entanto, complementar as ações nessa área com a capacitação de professores no atendimento às diversas deficiências [...] (LEME, 2015, p.151)
}

Sobre a possível interferência do professor na futura inserção dos alunos com NEE no mundo do trabalho, os participantes consideraram que o professor pode interferir encorajando o aluno, realizando orientação vocacional, promovendo atividades práticas, ensinando os conteúdos específicos das áreas do conhecimento e orientando sobre os direitos dos 
alunos visando uma formação crítica. Ainda mencionaram que consideram dificuldades ou não acreditam que o professor possa interferir nessa questão, por limitações estruturantes da sociedade ou pela não formação e capacitação para lidar com os alunos.

Conferimos ao professor papel relevante na contribuição para futura inserção dos alunos no mundo do trabalho visto a oportunidade que esses profissionais têm de estimular habilidades como a criatividade, autonomia, ética, iniciativa para articular novos saberes e trabalhar em equipe, que são tão importantes no percurso formativo dos trabalhadores quanto os conhecimentos técnicos de cada área de atuação profissional (BARBOSA; MOURA, 2013). Para além disso, os professores podem promover a criticidade dos alunos, orientá-los sobre seus direitos e ajudá-los na compreensão dos enfrentamentos necessários à vivência no mundo do trabalho dentro de uma sociedade capitalista (RAMOS, 2008).

Diante do exposto ponderamos a necessidade da promoção da formação continuada aos docentes, voltada à educação inclusiva, sobretudo aos professores regentes. Isso porque a fragilidade no que diz respeito a preparação para o atendimento dos alunos com NEE dificulta o desenvolvimento de práticas educativas que sejam promotoras da aprendizagem, bem como inibe que o profissional estimule habilidades que possam contribuir com a futura inserção dos estudantes no mundo do trabalho, fato que foi admitido pelos participantes.

Perante esses resultados, propomos a realização da Oficina pedagógica: (re)pensando a inclusão de estudantes com necessidades educacionais especiais e a formação para o mundo do trabalho, com o objetivo de promover um momento de formação e reflexão coletiva, em que os profissionais participantes da pesquisa pudessem (re)ver conceitos importantes sobre a Educação Inclusiva e sobre mundo do trabalho na perspectiva de emancipação do sujeito (SAVIANI, 2007). Tais reflexões foram propostas para que os profissionais considerassem o seu papel na 
promoção de práticas que favoreçam a aquisição de habilidades relacionadas a futura vivência dos alunos no mundo do trabalho.

Os resultados da aplicação da oficina foram satisfatórios pois os profissionais interagiram e pensaram coletivamente em soluções para melhorar o processo de inclusão e aprendizagem dos alunos com NEE na escola em que atuam. Além disso, ainda se dedicaram a elencar práticas integradoras que podem contribuir com a futura inserção dos alunos no mundo do trabalho, reconhecendo assim a possibilidade de que sua atuação possa se desdobrar na vivência laboral de seus alunos.

\section{Algumas considerações}

Diante das orientações voltadas ao Ensino Médio no que diz respeito a preparação dos alunos para o mundo do trabalho (BRASIL, 1996); (BRASIL, 2017), torna-se relevante repensar essa questão sob a perspectiva do trabalho como um princípio educativo, que contribui para a formação omnilateral, entendida como formação abrangente que contempla todas as dimensões humanas. Para que essa formação se efetive no ambiente escolar, é imprescindível que haja articulação entre teoria e prática, entre trabalho intelectual e manual por meio de práticas integradoras, que visem a superação da lógica excludente imposta pelo capitalismo.

No que se refere ao aluno com NEE, pensar em sua futura inserção no mundo do trabalho é de extrema importância, sendo uma questão que não deve ser negligenciada no processo de escolarização. Porém, na visão dos participantes dessa pesquisa, apesar de admitirem que os estudantes têm potencial para tal ingresso, nem todos se corresponsabilizaram diante dessa questão. Sendo que, entre os profissionais que se colocaram ativos nesse processo, se reconheceram principalmente como encorajadores, não como mediadores da formação basilar para que o aluno se desenvolvolva e consiga a futura inserção no mundo do trabalho. 
Uma formação efetiva para inclusão estaria expressa nas práticas realizadas pelos profissionais que estabelecessem relação direta com a aprendizagem dos alunos, estímulo de suas habilidades em detrimento às suas limitações, respeito às suas necessidades de aprendizagem e favorecimento da autonomia do aluno em relação a construção do conhecimento, estimulo de suas capacidades laborais com foco em suas potencialidades, compreendendo que a aprendizagem se realiza por meio da interação com o outro, seja colegas ou professores, no caso do contexto escolar.

Sendo assim, há um caminho a se construir ainda em relação a essa questão, pois poucos docentes relataram realizar adequações para favorecer ao aluno com NEE. E além disso ficou sinalizado um distanciamento entre professor e aluno, bem como entre PA e PR, o que denota uma desarticulação comprometedora do efetivo atendimento e consequente aprendizagem do aluno.

Cremos que a principal contribuição deste estudo tenha sido mostrar as relações complexas que se estabelecem no interior de nossas escolas que discursam serem inclusivas. Porém, camuflado sob esse discurso, ainda existem profissionais que se consideram incapazes ou enxergam dificuldades relevantes para que essa fala se materialize, seja por falta de formação ou condições concretas de trabalho. Ademais, foi de extrema importância evidenciar a necessidade da melhoria da relação entre PA e PR, para a implementação de um ensino colaborativo. Por fim, e igualmente importante, cuidamos ter contribuído para tencionar o debate sobre a concepção de trabalho como um princípio educativo para todos, e assim cooperar com a construção do itinerário formativo de Educação Profissional e Tecnológica com inclusão, a ser implementado não apenas na escola investigada, mas nas diversas escolas do nosso país.

\section{Referências}


ALVES, Z. M. M. B.; SILVA, M. H. G. F. D. da. Análise qualitativa de dados de entrevista: uma proposta. Paidéia, Ribeirão Preto, n. 2, p. 61-69, jul. 1992. Disponível em: <http://www.scielo.br/scielo.php?script=sci_arttext\&pid=S0103863X 1992000200007\&lng=en\&nrm=iso>. Acesso em: 15 Jan. 2018.

ARANHA, M. S. F. (org.). Estratégias para a educação de alunos com necessidades educacionais especiais. Ministério da Educação, Secretaria de Educação Especial: SEESP/MEC, Brasília, 2003.

BARBOSA, E. F.; MOURA, D. G. de. Metodologias ativas de aprendizagem na educação profissional e tecnológica. B. Tec. Senac, Rio de Janeiro, v. 39, n.2, p.4867, mai./ago. 2013.

BRASIL. Lei $\mathrm{n}^{0}$ 4.024, de 20 de dezembro de 1961. Fixa as Diretrizes e Bases da Educação Nacional. Brasília, 20 de dezembro de 1961. Disponível em: <http:// www.planalto.gov.br/ccivil_03/LEIS/L4024.htm>. Acesso em: 15 set. 2018.

. Lei ${ }^{0} 5.692$, de 11 de agosto de 1971. Fixa Diretrizes e Bases para o ensino $\overline{d e} 1^{\circ}$ e $2^{o}$ graus, e dá outras providências. Disponível em: <http://www .planalto.gov.br/ccivil_03/leis/L5692.htm>. Acesso em: 15 set. 2018.

Constituição Federal de 1988. Diário Oficial da União, 5 de outubro de 1988. Disponível em: <http://www.planalto.gov.br/ccivil_03/constituicao/ constituicaocompilado.htm>. Acesso em: 16 mar. 2018.

Lei n ${ }^{\circ} 9.394$ de 1996. Lei de Diretrizes e Bases da Educação Nacional. Brasília, 1996. Disponível em: <www.mec.gov.br/leis/ldb9394> Acesso em: 12 out. 2017.

. Ministério da Educação. Resolução CNE/CEB No 2, de 11 de setembro de 2001. Diretrizes Nacionais para a Educação Especial na Educação Básica. Secretaria de Educação Especial - MEC; SEESP, 2001. Disponível em: <http:// portal.mec.gov.br/seesp/arquivos/pdf/diretrizes.pdf>. Acesso em: 10 mar. 2018.

Decreto $\mathrm{n}^{0} 5.626$, de 22 de dezembro de 2005. Regulamenta a Lei $n^{\circ} 10.436$, de 24 de abril de 2002, que dispõe sobre a Língua Brasileira de Sinais - Libras, e o art. 18 da Lei $n^{\circ}$ 10.098, de 19 de dezembro de 2000. Diário Oficial República Federativa do Brasil, Brasília, DF, 23 dez. 2005. Disponível em: $<$ http://www.planalto.gov.br/ccivil_03/_Ato2004-2006/2005/Decreto/D5626.htm> Acesso em: 25 jul. 2018.

Política Nacional de Educação Especial na Perspectiva da Educação Inclusiva. 2008. Ministério da Educação. Secretaria de Educação Especial. Disponível em: <http://portal.mec.gov.br/arquivos/pdf/politicaeducespecial.pdf>. Acesso em: 28 jan. 2018.

Resolução $\mathrm{n}^{\circ}$ 4, de 2 de outubro de 2009. Institui Diretrizes Operacionais para o Atendimento Educacional Especializado na Educação Básica, modalidade Educação Especial. Disponível em: <http://portal.mec.gov.br /dmdocuments/rceb004 _09.pdf>. Acesso em: 28 jan. 2018. 
. Lei 13.415, de 16 de fevereiro de 2017. Altera a Lei 9.394/96 que estabelece as diretrizes e bases da educação nacional e 11.494/07 que regulamenta o FUNDEB $e$ dá outras providências. Diário Oficial da União, Brasília, DF, 17 fev. 2017. Disponível em: <http://www.planalto.gov.br/ccivil_03/_Ato2015-2018/2017/Lei/L134 15.htm> Acesso em: 25 mar. 2018.

- Resolução $\mathrm{n}^{\circ}$ 3, de 21 de novembro de 2018. Atualiza as Diretrizes Curriculares Nacionais para o Ensino Médio. Conselho Nacional de Educação. Câmara de Educação Básica. Diário Oficial da União, DF, 22 nov. 2018. Disponível em: $\quad<$ http://novoensinomedio.mec.gov.br/resources/downloads/pdf/dcnem.pdf $>$ Acesso em: 05 mai. 2019.

CARVALHO, R. E. Escola Inclusiva: a reorganização do trabalho pedagógico. 6. ed. Porto Alegre: Mediação, 2014.

CIAVATTA, M. A formação integrada: a escola e o trabalho como lugares de memória e de identidade. Trabalho Necessário, v. 3, n. 3, p. 1-20, 2005. Disponível em: <http://periodicos.uff.br/trabalhonecessario/article/view/6122> Acesso em: 18 nov. 2017.

CIAVATTA, M.; RAMOS, M. Ensino Médio e Educação Profissional no Brasil: dualidade e fragmentação. Retratos da Escola, Brasília, v. 5, n. 8, p. 27-41, jan./jun. 2011. Disponível em: <http://retratosdaescola.emnuvens.com.br/rde/article/view/ 45> Acesso em: 23 set. 2017.

DELL-MASSO, M. C. S. Educação e trabalho: temas a considerar para inclusão de pessoas com deficiência no mercado de trabalho. In: MIRANDA, T. G.; FILHO, T. A. G., (org.). O professor e a educação inclusiva: formação, práticas e lugares. Salvador: EDUFBA, 2012. p. 423-434.

GARCIA, R. M. C. Política de educação especial na perspectiva inclusiva e a formação docente no Brasil. Revista Brasileira de Educação, v. 18, n. 52, p. 101239, jan./mar. 2013. Disponível em: <http://www.scielo.br/pdf/rbedu/v18n52/07> Acesso em: 07 jun. 2019.

GHEDIN, E.; FRANCO, M. A. S. Questões de Método na Construção da Pesquisa em Educação. 2. ed. São Paulo: Cortez, 2011.

GIL, A. C. Como elaborar projetos de pesquisa. 4. ed. São Paulo: Atlas, 2008.

GOIÁS. Diretrizes operacionais da rede pública estadual de ensino de Goiás 2016/2017. Secretaria de Estado de Educação, Cultura e Esporte. Goiânia, 2016.

JESUS, D. M. de; EFFGEN, A. P. S. Formação docente e práticas pedagógicas: conexões, possibilidades e tensões. In: MIRANDA, T. G.; FILHO, T. A. G. (org.). $O$ professor e a educação inclusiva: formação, práticas e lugares. Salvador: EDUFBA, 2012. p. 17-24.

LAKATOS, E. M.; MARCONI, M. de A. Fundamentos de metodologia científica. 5. ed. São Paulo: Atlas, 2003. 
LEME, M. E. S. Deficiência e o mundo do trabalho: discursos e contradições. Campinas: Autores Associados, 2015.

MANTOAN, M. T. E. Inclusão Escolar O que é? Por quê? Como fazer? São Paulo: Summus, 2015.

MAZZOTTA, M. J. da S. Educação Especial no Brasil: história e políticas públicas. 6. ed. São Paulo: Cortez, 2011.

MINAYO, M. C. de S. (Org.). Pesquisa Social: Teoria, Método e Criatividade. 21. ed. Petrópolis: Vozes, 2002.

MOURA, D. H. Educação básica e educação profissional e tecnológica: dualidade histórica e perspectivas de integração. Holos, v. 2, p. 4-30, 2007. Disponível em: $<$ http://www.redalyc.org/articulo.oa?id=481549273001> Acesso em: 01 de jul. 2019.

MOUSINHO, R. et al. Mediação escolar e inclusão: revisão, dicas e reflexões. Rev. psicopedag., São Paulo, v. 27, n. 82, p. 92-108, 2010. Disponível em: <http://pepsic .bvsalud.org/scielo.php?script=sci_arttext\&pid=S0103-84862010000100010\&lng=pt $\& n r m=i$ iso $>$. Acesso em: 23 jun. 2019.

NASCIMENTO, S. E. A educação profissional: interfaces com a educação especial. In: DÍAZ, F. et al., (org.) Educação inclusiva, deficiência e contexto social: questões contemporâneas (online). Salvador: EDUFBA, 2009, p. 289-301. Disponível em: $<$ http ://books.scielo.org>. Acesso em: 04 jul. 2019.

RAMOS, M. Concepção do ensino médio integrado. Secretaria de Educação do Estado do Pará- Seminário Proeja. 08-09 mai. 2008. Disponível em: <https://te cnicadmiwj.files.wordpress.com/2008/09/texto-concepcao-do-ensino-medio-integra do-marise-ramos 1.pdf> Acesso em: 18 mar. 2019.

REDIG, A. G.; GLAT, R. Programa educacional especializado para capacitação e inclusão no trabalho de pessoas com deficiência intelectual. Ensaio, Rio de Janeiro, v. 25, n. 95, p. 330-355, abr. 2017. Disponível em: <http://www.scielo.br/ scielo.php?script=sci_arttext\&pid=S0104-40362017000200330\&lng=en\&nrm=iso $>$ Acesso em: 10 jan. 2018.

SAVIANI, D. Trabalho e Educação: Fundamentos ontológicos e históricos. Revista Brasileira de Educação, v.12, n. 34, p.152-165, jan./abr. 2007. Disponível em: <www.scielo.br/pdf/rbedu/v12n34/a12v1234.pdf>Acesso em: 18 jan. 2018.

Formação de professores: aspectos históricos e teóricos do problema no contexto brasileiro. Revista Brasileira de Educação, v. 14, n. 40, jan./abr. 2009. Disponível em: <http://www.scielo.br/pdf/rbedu/v14n40/v14n40a12> Acesso em: 20 out. 2018.

SEVERINO, J. A. Metodologia do Trabalho Científico. 23. ed. São Paulo: Cortez, 2007. 
SILVA, A. F. da; LEITE, T. S. Adequações curriculares e estratégias de ensino em turmas inclusivas: um estudo exploratório no $1^{\circ}$ Ciclo. Invest. Práticas, Lisboa, v. 5, n. 2, p. 44-62, set. 2015. Disponível em: <http://www.scielo.mec. pt/scielo. php ?script $=$ sci_arttext\&pid $=\mathrm{S} 2182-13722015000200004 \& \operatorname{lng}=\mathrm{pt} \& \mathrm{nrm}=\mathrm{iso}>$. Acesso em 01 jul. 2019.

SILVA, M. R. da. A BNCC da reforma do ensino médio: o resgate de um empoeirado discurso. Educação em Revista, Belo Horizonte, v.34, p. 01-15, 2018.

UNESCO. The Salamanca Statement and frameworkfor action on special needs education: [Declaração de Salamanca]. Conferência Mundial sobre Educação para Necessidades Especiais: Acesso e Qualidade, realizada em Salamanca, Espanha, em 7-10 de junho de 1994. Genebra: Unesco, 1994.

YIN, R. K. Estudo de caso: planejamento e métodos. Tradução de Cristhian Matheus Herrera. 3. ed. Porto Alegre: Bookman, 2015.

ZABALA, A. A prática educativa: como ensinar. Porto Alegre: Artes Médicas, 1998.

Recebido em agosto de 2019.

Aprovado em novembro de 2019. 